\title{
Implication of the Cytochrome b Mutations in the Evolution of Breast Benign Tumors Among Senegalese Women
}

\author{
Daniel Doupa ${ }^{1}$, Jean Luc Faye ${ }^{1}$, Fatimata Mbaye ${ }^{1,2}$, Sidy Ka $^{3}$, Ahmadou Dem $^{3}$, Mamadou Kane ${ }^{2}$, \\ Mbacké Sembène ${ }^{1,2}$ \\ ${ }^{1}$ Department of Biology Animal, Faculty of Science and Technology, Cheikh Anta Diop University, Dakar, Senegal \\ ${ }^{2}$ Sudanian Sahel Animal Populations Biology (BIOPASS), Research Institute for Development, IRD / Bel-Air, Senegal \\ ${ }^{3}$ Cancer Institut, Faculty of Medicine, Pharmacy and Odontology, Cheikh Anta Diop University, Dakar, Senegal
}

Email address:

mameluc03knb@gmail.com (J. L. Faye)

\section{To cite this article:}

Daniel Doupa, Jean Luc Faye, Fatimata Mbaye, Sidy Ka, Ahmadou Dem, Mamadou Kane, Mbacké Sembène. Implication of the Cytochrome $\mathrm{b}$ Mutations in the Evolution of Breast Benign Tumors Among Senegalese Women. International Journal of Genetics and Genomics.

Vol. 3, No. 4, 2015, pp. 36-42. doi: 10.11648/j.ijgg.20150304.11

\begin{abstract}
While the studies linking the germ line mtDNA mutations to cancer raise many ambiguities because of its high genetic variability, the study of somatic mutations of this one, is proved to be decisive in the identifying of mutations involved in the genesis and evolution of tumors. In the present study, we determined the implication of the Cytochrome $\mathrm{b}$ mutations in the evolution of breast benign tumors among Senegalese women. This one is about, with the sequencing-PCR, to research mutations of Cytochrome $b$, to evaluate their importance among a benign tissues group compared to another healthy tissues group; and thence, to determine the effect of the natural selection on the observed variability. The analysis of mutations profiles of Cytochrome $\mathrm{b}$ in benign tissues allowed seeing that $50 \%$ of them have led to a change in amino acid and $12.5 \%$ to a shift in the reading frame. Moreover, the analysis of selection signature indicated that these mutations were subjected to a positive selection. The results also revealed that the population of benign cells was growing rapidly from an ancestral population sparse. These observations have enabled to accept the hypothesis that Cytochrome $\mathrm{b}$ mutations would be involved in the evolution of breast benign tumors among Senegalese women.
\end{abstract}

Keywords: Breast, Benign, Tumors, Cytochrome b, Variability, Evolution, Senegal

\section{Introduction}

Beside the degenerative diseases that dominate the sanitary table of our societies, cancer (or rather cancers) still remains one of the more complex challenges proposed to medicine in terms of understanding of these pathologies, diagnosis and treatments. Known since Antiquity, the tumors has been for a long time black boxes of which no explanatory key seemed able to open the doors. Very long, the table of tumors is confined itself to descriptions certainly accurate but getting obstinate on the absence of testable hypothesis. It was necessary to wait the beginning of $20^{\text {th }}$ century with the combined advances of cell biology and molecular biology for seeing appear the concepts by which could be apprehended the notion of cell transformation.

Indeed, the second half of the $20^{\text {th }}$ century has been dominated by genetic models of tumors that provided conceptual tools explaining tumor genesis and its evolution.
Thus breast cancer in women, occupying the first place in terms of incidence and mortality in the world [1], was at the heart of the fundamental research. It therefore constitutes a major concern of public health.

In Senegal, apart from breast cancer, which occupies the second place after gynecological cancers in women [2] and making the subject of multiple research, many women suffer during their life from non-cancerous breast disease but whose development of some of them constitutes a risk factor to breast cancer [3]. It's indeed, the multiplication of these benign tumors and their eventual risk of malignancy that have aroused our interest and ever since this question is asked: the process is it linked to a genetic event that able at term to favor the occurrence of breast cancer?

Thus, cancers being ruled by mutation-selection process [4], specific to our evolution, the study of the importance of these forces will enable us to better understand the story of the tumor cells, the distribution of genetic and phenotypic 
variability of tissues and ultimately to facilitate the identification of genes involved in tumorigenesis. The understanding of this mutation-selection process that influences the variability of the human genome is a subject of fundamental interest in population genetics and evolutionary biology. On the other hand, we put the focus on the influence of natural selection on the genetic variability of Cytochrome $\mathrm{b}$ in the evolution of benign breast tumors.

Thus, on the premise that the evolution of tumors related to their genetic patrimony, we put forth the assumption according to which mutations of Cytochrome $b$ would be involved in the evolution of breast benign tumors.

The general objective of this study is to determine the implication of genetic alterations of Cytochrome $b$ in the evolution of benign breast tumors among Senegalese women. From this general objective, it results from it like specific objectives to research for mutations of interest of Cytochrome $b$, to evaluate their importance among a benign tissues group compared to another healthy tissues group; and thence, to determine the effect of the natural selection on the observed variability.

\section{Materials and Methods}

\subsection{Subjects}

This study was carried out from benign tissue cells of a group of patients presenting a breast benign tumor and normal tissue cells of another group of individuals being used as controls. Subjects were taken care of at the Cancer Institute of Aristide Le Dantec hospital in Dakar. On the whole, forty-four (44) of benign tissue samples and thirtyfour (34) of healthy tissues samples were obtained at the time of surgery, then convey to the Sudanian Sahel Animal Populations Biology (BIOPASS) laboratory of the Research Institute for Development of Senegal, where they were frozen and stored in alcohol $96^{\circ}$.

\subsection{DNA Extraction, PCR Amplification and Sequencing}

The total DNA of breast tissue was extracted by the standard method of "Qiagen DNeasy Tissue Kit". The extraction protocol was described by Mbaye et al. in [5]. After extraction we have proceeded to the amplification of our interest gene: the Cytochrome b.

Indeed, the Cytochrome $b$, a region of more than $a$ thousand of basic pair of mitochondrial genome situated in position 14747 and 15887 in the human sequence [6], belongs to one of four complex that provide the transfer of electrons in the mitochondrial respiratory chain. It is the only one of the 11 subunits of cytochrome c oxidoreductase complex (complex III or cytochrome bc1 complex, EC 1.10.2.2) to be encoded by mtDNA [7, 8]. It forms, with cytochrome $\mathrm{cl}$ and the Rieske iron-sulphur protein, the catalytic core of the cytochrome bcl complex. Thus, significant changes in its amino acid sequence would have therefore a high probability to induce significant alteration of the catalytic function of this complex III. Consequently,
Cytochrome b mutations affecting its structure, could be one of the causality factors of tumorous development. This is what justifies its choice for this study.

The amplification was performed in a reactional volume of $50 \mu 1$ composed of $42 \mu \mathrm{l}$ of PCR mix containing: $23.8 \mu \mathrm{l}$ of MilliQ water, $5 \mu \mathrm{l}$ Buffer $(10 \mathrm{X})$ containing $\mathrm{Mg}^{2+}$ ions at an initial concentration of $15 \mathrm{mM}, 1 \mu \mathrm{l}$ of supplementary $\mathrm{MgCl}_{2}$, $2 \mu \mathrm{l}$ of dNTP, $5 \mu \mathrm{l}$ of each primer which are: H15915 (TCTCCA-TTT-CTG-GTT-TAC-AAG-AC) and L14723 (ACCAAT-GAC-ATG- AAA-AAT-CAT-GGT-T) and $0.2 \mu \mathrm{l}$ of polymerase Taq and of $8 \mu 1$ of DNA extract diluted to $1 / 10$. It was made in a thermocyclor of Eppendhorf type under the following conditions: an initial denaturation at $94^{\circ} \mathrm{C}$ for 3 minutes, followed of 40 cycles of denaturation at $94^{\circ} \mathrm{C}$ for 45 seconds; an hybridization at $50^{\circ} \mathrm{C}$ for 1 minute characterized by the fixing of the primers and elongation at $72^{\circ} \mathrm{C}$ for 1 minute 30 seconds and at the end a final elongation at $72^{\circ} \mathrm{C}$ for 10 minutes, followed of a hold of $10^{\circ}$ $\mathrm{C}$ at infinity. These stages thus enumerated constitute one cycle and provide a multiplication by 2 of the target DNA at each cycle 40 in number for this study.

The Cytochrome b sequencing was performed from $30 \mu \mathrm{l}$ of PCR products for each sample with the way-primer.

\subsection{Analyzes of the Sequences of Cytochrome b}

The data processing or sequence alignment enables to obtain a correct data set underlining the similarity between sequences. The Cytochrome $b$ sequences of the two tissue groups were aligned with the Bio Edit software version 7.0.5.3 [9] by using the Clustal W multiple Alignment algorithm [10]. After their alignment, the sequences were carefully checked and corrected manually before proceeding to the research of mutations.

The research of mutations enables to establish their profiles in order to determine the processes of order genomic which are the basis of variability. For that, the sequences of two groups of healthy and benign tissue first aligned, were submitted to the MITOMAP database in order to compare them with the revised Cambridge Reference Sequence [11]. The differences of sequences identified between the reference sequence and the two tissue groups were registered as somatic mutations of Cytochrome b. Besides, the type of mutation was listed according to whether it is about transition, transversion, insertion or deletion. Mutations were also reported according to whether or not they have been registered in the database. However, variations of sequences common to both healthy and benign tissue groups were marked as neutral polymorphisms. The significance of sequence variations between healthy and benign tissue groups was underlined by the Fisher exact test available in Mito Tool version 1.1.2 [12] with a level significance (P value) of 0.05 and a $95 \%$ confidence interval.

In order to evaluate the functional relevance of the detected mutations, their nature was highlighted according to whether it was about synonymous mutation, nonsynonymous or mutation causing a displacement of the reading frame. 
The haplogroups associated to different mutations were also highlighted in both tissue groups. Besides, the significance of differences between them was also evaluated by the Fisher exact test available in Mito Tool version 1.1.2 [12] with a significance level of 0.05 and a $95 \%$ interval confidence.

In order to give an account of local variations of DNA sequences of Cytochrome b (alleles), the indices of diversity and divergence such as the haplotype (Hd) and nucleotide (Pi) of Nei in [13] diversity were underlined under DnaSP Version 5.10.01 [14]. Following this one, we passed to the analysis of the inter-tissue genetic differentiation.

The analysis of genetic differentiation enables to give an account of the inter-tissue genetic structure of Cytochrome b. For this, two parameters were highlighted: the index of genetic differentiation (Fst) and the index of dissimilarity or genetic distance.

The determination of the index of genetic differentiation (Fst) of Cavalli-Sforza in [15] consists to measure the variations in allele frequency of SNP between tissues in order to detect positive selection events. It was done under Arlequin version 3.1 [16]. Its value is always included between 0 (when there is no structuring) and 1 (if there is genetic structure). Indeed, at a value of Fst corresponds a Pvalue enabling to assess according that this one is significant or not. Besides, the level of significance of Fst which was retained is 0.05 .

As for the determination of genetic distances of Nei in [13], it consists to evaluate the number of replacements of alleles which are intervened at the locus during evolution. It was done under MEGA 6 version 6.05 [17]. After that, we have proceeded to the highlighting of amino acid variations in inter-tissue level.

The highlighting of amino acid variations enables to evaluate the inter-tissue protein diversity. This one was based on the comparison of the frequencies of amino acids in the two tissue groups. Thus the Cytochrome b being an encoding gene, the nucleotide sequences of the tissues were translated into protein sequences under MEGA 6 version 6.05 [17]. Indeed, the translation was done by using the most appropriate reading frame. For a given RNA sequence, there are three possible reading frames corresponding to the sequence of base triplets along the portion. Thus, the best reading frame is the one that presents the least stop codon compared to the two other. Besides, the significance of amino acid frequency variations between healthy and benign tissue groups was highlighted by the Fisher exact test available in Mito Tool version 1.1.2 [12] with a level of significance (P value) of 0.05 and a $95 \%$ confidence interval. After the highlighting of amino acid variations, we passed to the last stage of analyzes, corresponding to the detection of selection molecular signature at tumorous level.

The detection of selection molecular signature enables to determine the selective order processes that are at the base of genetic variability, of its maintenance and of its evolution in the time and in the tumorous microenvironment. This one is based on tests that determine whether the mutations frequency spectrum is in accordance with expectations of the standard neutrality model. For this, different statistics were highlighted in order to measure the deviations in relation to neutrality in the distribution of allele frequencies within the tissues. These include, D of Tajima in [18], D and F of Fu \& $\mathrm{Li}$ in [19]. These tests were highlighted under Arlequin version 3.1 [16]. Thus, negative values of D of Tajima and D and $\mathrm{F}$ of $\mathrm{Fu} \& \mathrm{Li}$ indicate generally an excess of rare alleles, coherent with a positive or negative selection; whereas positive values of these statistics reflect generally an excess of alleles at intermediate frequency, had to the balancing selection. Besides, to discriminate between the positive and negative selection we have used the test of $\mathrm{dN} / \mathrm{dS}$ which detects the selection acting on loci encoding for proteins by comparing the ratio of non-synonymous substitutions ( $\mathrm{dN})$ to the one of synonymous substitutions (dS). Thus, in case of neutrality, synonyms and non-synonymous substitutions should occur at the same rate and we should find $\mathrm{dN} / \mathrm{dS}=1$. The negative selection of non-synonymous variants would result in $\mathrm{dN} / \mathrm{dS}<1$; whereas positive selection of such variants would result in $\mathrm{dN} / \mathrm{dS}>1$ [20]. Whole of manipulations and analyzes made, have enabled to obtain the following results.

\section{Results and Discussion}

Several somatic mutations were described as well in healthy tissue sequences as in benign tissue sequences. On the whole, 40 mutations were identified (Table 1) witch 16 specific to healthy tissue, 22 to benign tissue and 2 common to both healthy and benign tissue groups being able to be defined like neutral polymorphisms. Among these variations described, 21 were already reported in the database and 19 news variations. These variations of sequences testifies thus of the great variability of Cytochrome b like its genetic instability. Our observations confirm the results of the work of Legros et al. in [8] relating to the functional characterization of novel mutations in the human Cytochrome $b$ gene and those of Mbaye et al. in [5] relating to the penetrance of Cytochrome $b$ in breast cancer in Senegalese women. In order to evaluate the functional relevance of these mutations, we have examined indirect criteria such as the nature of the mutation and the conservation of mutated amino acids in the tumor cell population.

In the healthy tissue sequences $64.71 \%(22 / 34)$ of these have undergoes several mutations, with a frequency of $5.54 \%$ witch $72.22 \%$ are transitions and $27.78 \%$ transversions. Indeed, $66.67 \%$ of these are synonymous mutations (silent) and $33.33 \%$ non-synonymous mutations leading to an amino acid change.

However, in the benign tissue sequences, $72.73 \%(32 / 44)$ of them have undergoes several mutations, with a frequency of $6.59 \%$ which $58.33 \%$ are transitions, $29.17 \%$ transversions, $4.17 \%$ insertions and $8.33 \%$ deletions. Indeed, $37.5 \%$ of these are silent mutations, $50 \%$ missense mutations leading to a change in amino acid and $12.5 \%$ shifting 
mutations leading to a change in the reading frame.

Comparatively in healthy tissues sequences where only $33.33 \%$ of the mutations have led to an amino acid change, in benign tissues sequences, $50 \%$ of the mutations have led to an amino acid change and $12.5 \%$ to a change in the reading frame. Among these mutations, six (A15824G, C15849T, C15839T, C15849A, T15519C and G15521A) with significant differences were already reported in the MITOMAP database by others authors and were associate to breast cancer $[5,21]$. These observations let think that these mutations are of functional importance in the evolution of benign breast tumors. However, extensive biochemical and molecular studies would be necessary in order to determine their effect in the energy metabolism of tumor cells.

Table 1. Cytochrome b mutations in breast tissues.

\begin{tabular}{|c|c|c|c|c|c|c|c|}
\hline Mutations & $\begin{array}{l}\text { Type of } \\
\text { mutation }\end{array}$ & $\begin{array}{l}\text { Nature of } \\
\text { mutation }\end{array}$ & $\begin{array}{l}\text { Healthy tissues } \\
\text { (34) }\end{array}$ & $\begin{array}{l}\text { Benign tissues } \\
(44)\end{array}$ & $P$-value & Odds Ratio & Reported mutation \\
\hline $\mathrm{T} 15784 \mathrm{C}$ & Transition & syn: $P=>P$ & $6(17.65 \%)$ & $8(18.18 \%)$ & 0.579 & 0.768421 & + \\
\hline A15824G & Transition & non-syn: $\mathrm{T}=>\mathrm{A}$ & 0 & $10(23.73 \%)$ & $5.6^{\mathrm{e}-10 *}$ & - & + \\
\hline $\mathrm{C} 15849 \mathrm{~T}$ & Transition & non-syn:T=>I & 0 & $4(9.09 \%)$ & $0.001 *$ & - & + \\
\hline $\mathrm{C} 15839 \mathrm{~T}$ & Transition & syn:L=>L & 0 & $2(4.54 \%)$ & $0.016 *$ & - & + \\
\hline C15849A & Transversion & non-syn: $\mathrm{T}=>\mathrm{N}$ & 0 & $2(4.54 \%)$ & $0.016 *$ & - & + \\
\hline $\mathrm{T} 15519 \mathrm{C}$ & Transition & non-syn: $\mathrm{L}=>\mathrm{P}$ & 0 & $6(13.64 \%)$ & $6.7^{\mathrm{e}-06} *$ & - & + \\
\hline G15521A & Transition & non-syn: $\mathrm{A}=>\mathrm{T}$ & 0 & $2(4.54 \%)$ & $0.016 *$ & - & + \\
\hline $\mathrm{C} 15577 \mathrm{CC}$ & Insertion & Frmshft & 0 & $1(2.27 \%)$ & 0.197 & - & \\
\hline C15582d & Deletion & Frmshft & 0 & $1(2.27 \%)$ & 0.197 & - & \\
\hline G15596d & Deletion & Frmshft & 0 & $1(2.27 \%)$ & 0.197 & - & \\
\hline C15789G & Transversion & non-syn: $\mathrm{T}=>\mathrm{S}$ & 0 & $1(2.27 \%)$ & 0.197 & - & \\
\hline $\mathrm{C} 15604 \mathrm{~T}$ & Transition & syn: $\mathrm{N}=>\mathrm{N}$ & $7(20.59 \%)$ & 0 & $1.9^{\mathrm{e}-06} *$ & - & + \\
\hline $\mathrm{T} 15622 \mathrm{G}$ & Transversion & syn: $\mathrm{L}=>\mathrm{L}$ & $10(29.41 \%)$ & 0 & $1.1^{\mathrm{e}-08} *$ & - & \\
\hline A $15546 \mathrm{C}$ & Transversion & non-syn: $\mathrm{H}=>\mathrm{P}$ & $4(11.76 \%)$ & 0 & $0.001 *$ & - & \\
\hline $\mathrm{C} 15569 \mathrm{~T}$ & Transition & syn:L=>L & $4(11.76 \%)$ & $1(2.27 \%)$ & $0.023 *$ & 5.28713 & \\
\hline A15613G & Transition & syn:G=>G & $3(8.82 \%)$ & 0 & $0.004 *$ & - & + \\
\hline C15608A & Transversion & non-syn: $L=>M$ & $2(5.88 \%)$ & 0 & $0.034 *$ & - & \\
\hline A15794T & Transversion & non-syn:I=>F & 0 & $1(2.27 \%)$ & 0.197 & - & \\
\hline A15799T & Transversion & syn:G=>G & 0 & $1(2.27 \%)$ & 0.197 & - & \\
\hline $\mathrm{A} 15802 \mathrm{~T}$ & Transversion & non-syn:Q=>H & 0 & $1(2.27 \%)$ & 0.197 & - & \\
\hline G15553A & Transition & syn:K=>K & 0 & $1(2.27 \%)$ & 0.197 & - & + \\
\hline $\mathrm{C} 15641 \mathrm{~T}$ & Transition & non-syn: $\mathrm{L}=>\mathrm{F}$ & 0 & $1(2.27 \%)$ & 0.197 & - & + \\
\hline C15832G & Transversion & non-syn:I=>M & 0 & $1(2.27 \%)$ & 0.197 & - & \\
\hline $\mathrm{T} 15512 \mathrm{C}$ & Transition & non-syn: $Y=>H$ & 0 & $1(2.27 \%)$ & 0.197 & - & + \\
\hline $\mathrm{T} 15530 \mathrm{C}$ & Transition & syn:L $=>\mathrm{L}$ & 0 & $1(2.27 \%)$ & 0.197 & - & + \\
\hline $\mathrm{C} 15838 \mathrm{~T}$ & Transition & syn:I=>I & $1(2.94 \%)$ & 0 & 1 & - & \\
\hline $\mathrm{C} 15580 \mathrm{~T}$ & Transition & syn: $S=>S$ & $1(2.94 \%)$ & 0 & 1 & - & \\
\hline C15589A & Transversion & syn: $\mathrm{L}=>\mathrm{L}$ & $1(2.94 \%)$ & 0 & 1 & - & + \\
\hline $\mathrm{T} 15586 \mathrm{C}$ & Transition & syn:I=>I & $1(2.94 \%)$ & 0 & 1 & - & + \\
\hline $\mathrm{C} 15587 \mathrm{~T}$ & Transition & non-syn: $L=>F$ & $1(2.94 \%)$ & 0 & 1 & - & \\
\hline $\mathrm{C} 15595 \mathrm{~T}$ & Transition & syn: $S=>S$ & $1(2.94 \%)$ & 0 & 1 & - & + \\
\hline $\mathrm{C} 15577 \mathrm{~T}$ & Transition & syn: $\mathrm{L}=>\mathrm{L}$ & $1(2.94 \%)$ & 0 & 1 & - & \\
\hline G15734A & Transition & non-syn: $A=>T$ & $1(2.94 \%)$ & 0 & 1 & - & + \\
\hline $\mathrm{C} 15574 \mathrm{~T}$ & Transition & syn:F=>F & 0 & $1(2.27 \%)$ & 0.197 & - & + \\
\hline A15851G & Transition & non-syn:I=>V & 0 & $1(2.27 \%)$ & 0.197 & - & + \\
\hline $\mathrm{T} 15629 \mathrm{C}$ & Transition & syn: $L=>L$ & 0 & $1(2.27 \%)$ & 0.197 & - & + \\
\hline $\mathrm{A} 15835 \mathrm{~T}$ & Transversion & syn: $\mathrm{L}=>\mathrm{L}$ & 0 & $1(2.27 \%)$ & 0.197 & - & \\
\hline
\end{tabular}

syn : synonym mutation non-syn : non synonym mutation
+ : reported mutation

* : significant difference
Nevertheless, Dasgupta et al. in [22] in a study relating to mutations of Cytochrome $b$ in tumor growth of bladder cancer, have shown by a murine xenograft and human model of bladder cancer, the functional effect of overexpression of a 21-bp deletion mutation of Cytochrome b. They have been able to demonstrate that this on induced significant tumor growth by triggering rapid cell cycle progression through up-regulation of the nuclear factor-kB2 signaling pathway.

The mutations detected in the two groups of healthy and benign tissue were associated to different haplogroups (Table 2). Thus, 5 haplogroups were described which 3 (H, M and L) 
common to the two tissue groups. However, the L haplogroup is in the majority in benign tissue with a significance level lower than 0.05 for an Odds Ratio of (0.054) and confidence intervals (CI) of (0.006-0.451). This predominance can be explained by the functional importance that its haplotypes could play in the evolution of benign breast tumors.

Table 2. Haplogroups associated to different mutations.

\begin{tabular}{llllll}
\hline Haplogroups & $\begin{array}{l}\text { Healthy } \\
\text { tissues }\end{array}$ & $\begin{array}{l}\text { Benign } \\
\text { tissues }\end{array}$ & P-value & $\begin{array}{l}\text { Odds } \\
\text { Ratio }\end{array}$ & C.I \\
\hline $\mathrm{H}$ & 16 & 14 & 0.051 & 3.428 & $\begin{array}{l}1.064- \\
11.043\end{array}$ \\
$\mathrm{R}$ & & & & - & - \\
$\mathrm{M}$ & 4 & 0 & $0.023 *$ & - & $0.061-$ \\
$\mathrm{L}$ & 1 & 2 & 1 & 0.714 & 8.398 \\
$\mathrm{~B}$ & 1 & 15 & $0.001 *$ & 0.054 & 0.006 \\
\hline
\end{tabular}

The analysis of the Cytochrome $b$ genetic structure in the two groups of tissue (Table 3 ) has revealed low intra-tissue genetic distances of (0.046) and (0.016) respectively in healthy tissue and benign tissue. This one shows also a low inter-tissue genetic distance of (0.049). In addition to low intra-tissue genetic distances observed, we note also a significant Fst of (0.36942) with a P-value lower than 0.05 corresponding to the level of significance of the Fst. The low inter-tissue genetic distance and the significant Fst are characteristic of a beginning of genetic differentiation between healthy and benign tissue; which besides express the benign state of tumor cells. The low intra-tumorous genetic distance $(0.016)$ can be explained by the monoclonal origin of mammary tumors [23] of which development rests on a succession of waves of clonal expansions. Indeed, a tumor is composed of different subpopulations of abnormal cells having for common points the alterations occurred precociously and whose genesis follows the laws of an evolutionary continuum spatiotemporal [24].

However, in spite of this differentiation between healthy and benign tissue, no significant difference could be noted in the frequency distribution of amino acids between the two tissue groups.

Table 3. Genetic distances and index of differentiation (Fst).

\begin{tabular}{llll}
\hline Group of tissues & $\begin{array}{l}\text { Intra-tissular } \\
\text { genetic distances }\end{array}$ & $\begin{array}{l}\text { Inter-tissular } \\
\text { genetic distances }\end{array}$ & Fst \\
\hline $\begin{array}{l}\text { Healthy tissues } \\
\text { Benign Tissues }\end{array}$ & 0.046 & 0.049 & 0.36942 \\
\hline
\end{tabular}

The detection of signature of natural selection in benign tissue based on the spectrum of allele frequencies (Table 4), indicates that the D of (Tajima) tests corresponding to ($2.39301)$ and the $\mathrm{D}$ and $\mathrm{F}$ of $(\mathrm{Fu} \& \mathrm{Li})$ respectively (4.01614) and (-4.07023) are significantly negative. This is characteristic to an excess of rare alleles, coherent with a positive or negative selection. We note also that the $\mathrm{dN} / \mathrm{dS}$ ratio that was used to discriminate according to it's about a positive or negative selection, indicates a value of 1.33333 higher to 1 , characteristic of a positive selection [20].

Table 4. Neutrality tests in benign tissues.

\begin{tabular}{lll}
\hline Statistique tests & Benign tissues & P-value \\
\hline D of Tajima & -2.39301 & 0 \\
D of Fu and Li & -4.01614 & 0.02 \\
F of Fu and Li & -4.07023 & 0.02 \\
dN/dS & 1.33333 & - \\
\hline
\end{tabular}

This positive selection, called also adaptive selection causes the increase in frequency of variants that confer an advantage in the tumorous microenvironment [25]. This can be explained by an adaptation of tumorous cells to the stroma become permissive. Indeed, the Cytochrome b being a key component of oxidative phosphorylation system, had confer by its mutations, to tumorous cells a selective advantage in their adaptation, survival and proliferation mechanisms. This is besides confirmed by the evolution state of the tumorous cell population, which reveals a rapid growth of population from an ancestral population to low numbers, characterized by a strong haplotype diversity (Hd) of (0.949) for a low nucleotide diversity $(\mathrm{Pi})$ of (0.02438) (Table 5).

Table 5. Indices of diversity and divergence.

\begin{tabular}{lllll}
\hline & h & Hd & Pi $(\boldsymbol{\pi})$ & $\boldsymbol{\theta} \boldsymbol{\pi}$ \\
\hline Healthy tissues & 26 & $0.982 \pm 0.012$ & $0.04504 \pm 0.00224$ & 0.04792 \\
Benign tissues & 27 & $0.949 \pm 0.019$ & $0.02438 \pm 0.00604$ & 0.02520 \\
\hline
\end{tabular}

$\mathrm{h}$ : number of haplotypes

Hd: haplotype diversity

$\operatorname{Pi}(\pi)$ : nucleotide diversity of Nei $\theta \pi$ : theta per site from $\mathrm{Pi}$

Our observations confirm the results of a great number of researchers as for the correlation between mtDNA mutations and tumorigenesis; and yet controverted by another group of researchers. To this effect, two theories are contrasted: the first stipulate that the mtDNA mutations simply arise by chance in tumor progenitor cells without any physiological advantage or tumorigenic requirement. By contrast, the other theory states that these mtDNA mutations stimulate tumor and contribute to tumorigenesis and tumor progression.

In the first theory the authors have hypothesized that the mtDNA mutations in cancerous cells originated from tumorigenesis. Some authors such as Beckman \& Ames in [26]) assert that many mtDNA mutations occur at random further to oxidative damage generated by tumor cells. Others such as Warburg in [27] pioneered the study of mitochondrial changes in tumor cells, Coller et al. in [28], and Chinnery et al. in [29] assert that mtDNA mutations do not damage the energy metabolism of cells and that these mutations had the ability to fix or disappear in cells through the mechanism of genetic drift. Moreover, Vega et al. in [30] postulated that the mtDNA mutations in tumor cells were hitchhike mutations and did not play a role in tumorgenesis.

However, the authors of the second theory suggest that the mtDNA mutations in tumor cells acted as a stimulus for tumors and contributed to tumorigenesis and tumorous progression. Indeed, some of them such as Hayashi et al. in 
[31] and Dani et al. in [32] have showed that the dysfunction of the mitochondrial genome greatly affected the survival and the proliferation of tumorous cells. Others have also demonstrated that the increasing of ROS caused by mtDNA mutations contributed to tumorigenesis and tumorous progression $[33,34]$.

Finally, it agree upon admit that mitochondria play an important role in cellular energy metabolism, in the production of free radicals and in apoptosis. Thus, all dysfunction of the mitochondria further to mutations in its genome, affecting its function, could be one of the causality factors of tumorigenesis. However, although the role of mtDNA mutations in tumorigenesis has been studied in detail by various approaches, the conclusions to date remain controverted.

\section{Conclusion}

In this study, we successfully highlighted the functional importance of Cytochrome b mutations in the evolution of breast benign tumors. $50 \%$ of the mutations identified in benign tissues have led to an amino acids change and $12.5 \%$ to a change of the reading frame. Moreover, these mutations are subject to a positive selection and that the demographic of benign tissue indicates a rapid growth of population from an ancestral population to low number. These results have allowed accepting the hypothesis of this study that the genetic changes of Cytochrome $b$ would be involved in the evolution of benign breast tumors.

However, it does not remain about it less than the all variants (mutations) identified in this study as being potentials targets of positive selection, could have a functional impact in the evolution of benign breast tumors. Indeed, though it exist many reports on Cytochrome b mutations in divers tumors of different anatomical origin, the functional effect of these in metabolism and cell growth is not clearly elucidated. Thus, this study having a predictive role, our results open the way for future biochemical, proteomic and clinical studies in order to determine the effect of these somatic mutations in the energy metabolism of tumor cells.

Nevertheless, populations genetic, via the detection of selection signature at genomic level, constitute a good alternative to clinical and epidemiological studies in the research of genes or variants implicated in cancers and in human diseases.

\section{References}

[1] IARC: International Agency for Research on Cancer (2012) World Estimate Cancer Incidence, All Ages, Female. IARC Press.

[2] Dem A, Traoré B, Dieng MM., Diop PS, Ouajdi T, Lalami MT, Diop M, Dangou JM, Touré P (2008) Gynaecological and breast cancers in Cancer Institut of Dakar. French-speaking Journal of Studies and Reseach / Health 18 (1): 25-29.
[3] Desjardins S (2010) Analyze genes candidates to breast cancer implicated in the interactions with brca1 and brca2. Thesis of doctorate, Physiology-Endocrinology. Québec: Laval University, $234 \mathrm{p}$.

[4] Bénard J, Larsen CJ (2013) Explicative models of cancer biology: an enlarged vision. Bulletin of Cancer 100: 697-713.

[5] Mbaye F, Dem A, Fall M, Sembène M (2012) Implication of the Cytochrome $\mathrm{b}$ nucleotide and protein mutations in the occurrence of breast cancer in Senegal. International Journal of Applied Biology and Pharmaceutical Technology 3(2): 107114.

[6] Anderson S, Bankier AT, Barrel BG, DE Bruijn MHL, Coulson AR, Drouin J, Eperon IC, Nierlich DP, Roe BA, Sanger F, Schreier, Smith AJ, Staden R, Young IG (1981) Sequence and organization of the human mitochondrial genome. Nature 290: 457-465.

[7] Iwata S, Lee JW, Okada K (1998) Complete structure of the 11 subunit bovine mitochondrial cytochrome bc1 complex. Science 281: 64-71.

[8] Legros F, Chatzoglou E, Frachon P, Ogier de Baulny HA, Laforêt P, Jardel C, Godinot C, Lombès A (2001) Functional characterization of novel mutations in the human Cytochrome b gene. European Journal of Human Genetics 9: 510-518.

[9] Hall TA (1999) Bioedit: a user-friendly biological sequence alignment editor and analysis program for Windows 95/98/NT. Nucleic Acids Symposium 44: 211-232.

[10] Thompson JD, Higgins DG, Gibson TJ (1994) CLUSTAL W: improving the sensitivity of progressive multiple sequence alignment through sequence weighting, position-specific gap penalties and weight matrix choice. Nucleic Acids Research 22:4673-4680.

[11] Andrews RM, Kubacka I, Chinnery PF, Lightowlers RN, Turnbull DM, Howell N (1999) Reanalysis and revision of the Cambridge reference sequence for human mitochondrial DNA. Nature Genetics 23 (2): 147.

[12] Long F, Yong-Gang Y (2013) An update to MitoTool: Using a new scoring system for faster mtDNA haplogroup determination. Mitochondrion 3: 360-363.

[13] Nei M (1987) Molecular evolutionary genetics. Columbia University Press, New York.

[14] Librado P, Rozas J (2009) DnaSP v5: A software for comprehensive analysis of DNA polymorphism data. Bioinformatics 25: 1451-1452.

[15] Cavalli-Sforza LL (1966) Population structure and human evolution. Proceedings of the Royal Society of London B: Biology Science 164: 362-379.

[16] Excoffier L, Laval LG, Schneider S (2005) Arlequin V3.1: An integrated software package for population genetics data analysis. Evolutionary Bioinformatics Online 1: 47-50.

[17] Tamura K, Peterson D, Peterson N, Stecher G, Nei M, Kumar S (2013) MEGA6: Molecular Evolutionary Genetics Analysis using Maximum Likelihood, Evolutionary Distance, and Maximum Parsimony Methods. Molecular Biology \& Evolution 28 (10): 2731-2739.

[18] Tajima F (1989) Statistical method for testing the neutral mutation hypothesis by DNA polymorphism. Genetics 123 (3): 585-595. 
[19] Fu YX, Li W H (1993) Statistical tests of neutrality of mutations. Genetics 133: 693-709.

[20] Vasseur E, Quintana-Murci L (2013) The impact of natural selection on health and disease: uses of the population genetics approach in humans. Evolutionary Applications 6 (4): 596-607.

[21] Elliott HR, Samuels DC, Eden JA, Relton CL, Chinnery PF (2008) Pathogenic Mitochondrial DNA Mutations Are Common in the General Population. The American Journal of Human Genetics 83: 254-260.

[22] Dasgupta S, Hoque MO, Upadhyay S (2008) Mitochondrial Cytochrome b Gene Mutation Promotes Tumor Growth in Bladder Cancer. Cancer Research 68:700-706.

[23] Nkondjock A, Ghadirian P (2005) Risk Factors to breast cancer. Medicine/Sciences 21(2): 175-180.

[24] Guinebretière JM, Menet E, Fourme E (2007) The histological risk, report of the French-speaking higher course of cancerology. Saint paul de Vence. Springer-Verlag France, edition 2007, Paris

[25] Sabeti PC, Schaffner SF, Fry B, Lohmueller J, Varilly P, Shamovsky O, Palma A, Mikkelsen TS, Altshuler D, Lander ES (2006) Positive natural selection in the human lineage. Science 312: 1614-1620.

[26] Beckman KB, Ames BN (1997) Oxidative decay of DNA. Journal of Biological Chemistry 272: 19633-19636.

[27] Warburg O (1956) On the origin of cancer cells. Science 123: 309-314.
[28] Coller HA, Khrapko K, Bodyak ND, Nekhaeva E, HerreroJimenez P, Thilly WG (2001) High frequency of homoplasmic mitochondrial DNA mutations in human tumors can be explained without selection. Nature Genetics 28: 147-150.

[29] Chinnery PF, Samuels DC, Elson J, Turnbull DM (2002) Accumulation of mitochondrial DNA mutations in ageing, cancer, and mitochondrial disease: is there a common mechanism? Lancet 360: 1323-1325.

[30] Vega A, Salas A, Gamborino E, Sobrido MJ, Macaulay V, Carracedo A (2004) mtDNA mutations in tumors of the central nervous system reflect the neutral evolution of mtDNA in populations. Oncogene 23: 1314-1320.

[31] Hayashi J, Takemitsu M, Nonaka I (1992) Recovery of the missing tumorigenicity in mitochondrial DNA-less HeLa cells by intro- duction of mitochondrial DNA from normal human cells. Somatic Cell Molecular Genetics 18: 123-129.

[32] Dani MA, Dani SU, Lima SP (2004) Less deltamtDNA4977 than normal in various types of tumors suggests that cancer cells are essentially free of this mutation. Genetics Molecular Research 3: 395-409.

[33] Esposito LA, Melov S, Panov A, Cottrell BA, Wallace DC (1999). Mitochondrial disease in mouse results in increased oxidative stress. Proceedings of the National Academy of Sciences of the United States of America 96: 4820-4825.

[34] Bostwick DG, Alexander EE, Singh R (2000) Antioxidant enzyme expression and reactive oxygen species damage in prostatic intraepithelial neoplasia and cancer. Cancer 89:123134. 